\title{
A Survey on Civic Consciousness in Contemporary China
}

\author{
Tong Huasheng ${ }^{1}$ \\ ${ }^{1}$ School of Political Science, Southwest Jiaotong University, China \\ Correspondence: Tong Huasheng, School of Political Science, Southwest Jiaotong University, $111,1^{\text {st }}$ Section, \\ $2^{\text {nd }}$ Ring Road North, Chengdu 610031, China. Tel: 86-28-8760-0379. E-mail: tonghuasheng@126.com
}

Received: July 20, 2012 Accepted: August 2, 2012 Online Published: September 26, 2012

doi:10.5539/ies.v5n6p110 URL: http://dx.doi.org/10.5539/ies.v5n6p110

\begin{abstract}
In the current stage of China's modernization construction and social transformation, the cultivation of sound civic consciousness in the context of the servant consciousness lasting for thousands of years is the premise to cultivate citizens with civic rights and responsibilities, the foundation to achieve the modernization of individuals or the all-round development of individuals and the key to realize social modernization in this country. Through an empirical research we could see that a kind of modern civic consciousness in Chinese citizens' mind is taking shape, but the influence of the servant consciousness is still obdurately existing, so on the whole, Chinese civic consciousness is relatively insufficient. And the current situation, the system of contents and methodology to cultivate the sound civic consciousness should be taken seriously.
\end{abstract}

Keywords: civic consciousness, current situation, survey, China

\section{Introduction}

Civic consciousness is a form of social consciousness co-existing with the concept of citizen. In a narrow sense, in contrast to servant consciousness characterized by anaclisis, civic consciousness mainly refers to the cognition of a citizen's qualification or status with equal civic rights and obligations. The term of "citizenship" has some kinds of meanings: the legal status and political status; involving the public life and affairs; citizenship education. (Huddleston and Kerr 2006, p. 2) And meanwhile, "citizenship typically refers to the relationship between the individual and the community, state, or nation."(Kathleen Knight-Abowitz 2009, p.128) So in a broad sense, modern civic consciousness consists of the following aspects: the initiative knowledge of the relationship between individuals and the state or society; the rational cognition of citizenship, civic rights and liabilities and civic virtues; the internalization and identification of the social behavioral norms and basic values.

Contemporary China is derived from a feudal autocratic society with a history of over two thousand years and is now in a period of sharp transition of economy, politics and culture. The servant consciousness in the traditional feudal autocratic society has been widely criticized and gradually abandoned, but the modern context about civic consciousness hasn't been established. The unevenly-developed traditional and modern elements and national and exotic cultures have undoubtedly been influencing citizens' ideologies. Citizens are increasingly becoming cold, fickle, parochial and perplexed. So in this transitional period of China, citizenship education or civic education will be necessary and especially important. "Civic education can be defined as the acquisition of knowledge, skills, and dispositions that are needed for effective and responsible citizenship in a democratic society." (Monalisa 2008, p.79) And in the process of citizenship education, the cultivation of modern civic consciousness in the basis of servant consciousness existing for thousands of years is the premise to cultivate citizens with civic rights and responsibilities, the foundation to achieve the modernization of individuals or individuals' all-round development and the key to realize socialist modernization in China. So the Seventeenth National Congress of the CPC emphasized "We need to step up education about citizenship and establish socialist concepts of democracy, the rule of law, freedom, equality, equity and justice.” (Hu Jintao, 2007)

\section{Literature Review}

In the process of civic education in western countries, some theories on civic education contained in Liberalism, Republicanism, Communitarianism and Multiculturalism should be mentioned. Liberalism is based on individualism. Either classical liberalists like Lock or new liberalists such as Dewey, Roosevelt, Keynes and Rawls promoted freedom and valued rights. They thought that citizens in a free society should have such civic consciousnesses as freedom, equality, justice and tolerance. Republicanism holds that the state is the ownership 
of individuals and individuals should first consider the public interest. Therefore, republicanism emphasizes such civic consciousnesses as national identity, democratic consultation and active participation. Communitarianism emphasizes the value of the communities such as the nation and the state. In Communitarianists' view, ideal citizens should focus on the public interests of a community and should also enhance their own consciousnesses of loyalty, belonging and identity to the community. Multiculturalism holds that today's society is a diverse and heterogeneous one, so it emphasizes citizens' admission and tolerance to different cultures and values in order to properly solve conflicts between citizens. These representative theories interpret, from different perspectives, what civic consciousness of good citizens is and how a certain society makes ideal citizens. In spite of some defects of these theories, their aim to cultivate good citizens with civic consciousnesses adapting to the development of a society or a nation is clear.

In China, since the Opium War, some persons influenced by western democratic thoughts have realized that the long-lasting servant consciousness in the minds of Chinese people have seriously hampered the development of the society. They wished to enrich the country and strengthen the people, and strengthening the people mainly referred to making the people realize their own master status of a nation. And today, with the advancement of democratic process, many people begin to pay close attention to the cultivation of civic consciousness and a gradually increasing number of researchers focus their studies on civic consciousness. Researches in China are mainly involved in the following aspects: definition of civic consciousness, analysis of the cause about lack of Chinese civic consciousness, the conditions of generation and development of modern civic consciousness, the significance of the cultivation of civic consciousness, the content system of civic consciousness education, and the ways of cultivating modern civic consciousness. But as a matter of fact, most of the studies are mainly limited to the significance of civic consciousness and the content of civic consciousness, just staying around the research of academic theories, but there are few empirical researches on the current situation of the Chinese civic consciousness, which should be the foundation to carry on the researches and to improve the civic consciousness of every citizen in China.

In order to learn the current situation of contemporary Chinese civic consciousness, and put forward some practical suggestions to nurture qualified and responsible citizens, we conducted a survey on the civic consciousness of Chinese citizens.

\section{Methods}

The survey was conducted in four months from June to September, 2011. It mainly employed the method of stratified random sampling, and those surveyed are from companies, factories, schools in South China, Central China and Northwest China, and also from all walks of life in different cities and rural areas of Southwest China. 1820 questionnaires were distributed and 1658 were returned, of which 1590 were valid. And meanwhile, 258 questionnaires were acquired with the aid of a special online survey platform Ask Form. Altogether, 1921 questionnaires were acquired and the response rate of the questionnaires is $92.22 \%$. And the number of valid questionnaires is 1848 , accounting for $88.72 \%$.

According to the different contents of civic consciousness, this questionnaire is roughly divided into a few aspects, including the subject consciousness, national consciousness, political participation consciousness, legal consciousness, moral consciousness, ecological civilization consciousness and global consciousness. The survey wishes to learn how citizens understand the concept of civic consciousness itself and what kinds of civic consciousness they have. The questionnaire mainly consists of multiple-choice questions, and it is easy for those surveyed to answer them and also convenient for us to sort and code the questionnaires.

After the process of data collection, it is necessary to provide the readers or the researchers with what are contained in the data. In the survey, most of the data collected were dealt with by using Version 19.0 of IBM SPSS (Statistics Package for Social Science) and a small part of the data were dealt with Microsoft Office Excel 2003. Descriptive statistics were mainly used to analyze the data, and the frequencies and average percentages were used to describe and compare the results.

\section{Basic Information of the Samples}

The basic information of the surveyed samples includes the gender, age, residence, educational level and profession/identity. The citizens under 12 years were not expected to fill in the questionnaires, because they are still being enlightened in kindergartens or schools and it is not easy for them to express accurately their ideas. As for the professions or identities, the samples are divided into 9 types according to the theory of social stratification, referring to the standard of professional classification and based on the objective and content of the survey. The frequencies of the relevant variables are as follows. 
Gender: male(57.7\%), female(42.3\%); Age: 12-17(25.3\%), 18-21(17.3\%), 22-39(39.8\%), 40-49(14.2\%), 50 and above(3.5\%); Residence: large and medium-sized city(33.9\%), small town(21.3\%), rural area(44.8\%); Educational level: primary and below(6.0\%), junior middle school(21.5\%), senior middle school or technical secondary school(35.0\%), college or university degree(28.2\%), master degree or above(9.3\%); Profession/identity: civil servants(4.6\%), clerks of other institutions(7.4\%), enterprise employees(19.0\%), self-employed entrepreneurs(1.7\%), freelancers( $8.1 \%)$, migrant workers from countryside to town(6.9\%), peasants(6.3\%), unemployed adults(5.0\%) and students(41.0\%).

\section{Results}

\subsection{Citizens' Understanding of Civic Consciousness}

How citizens understand the concept civic consciousness or what content citizens think civic consciousness contains will directly influence the formation of their own modern civic consciousness. So a question was set in the questionnaire about citizens' understanding of the concept "civic consciousness". Those surveyed were asked to select 5 words they considered to be most related to civic consciousness from the 21 words given.

The result shows that more than half of the respondents chose the following words: abidance by law $(67.6 \%)$, rights $(66.6 \%)$, obligations $(64.1 \%)$, integrity $(60.1 \%)$, equality $(55.2 \%)$, responsibility $(54.1 \%)$, patriotism $(53.8 \%)$ and democracy $(50 \%)$. That is to say, most of the respondents think that the qualities above should be what a good citizen has in a modern society. Although some citizens are not sure about what civic consciousness accurately is, yet from their responses we could see that their rough understanding about the concept will undoubtedly be helpful in the cultivation of their modern civic consciousness.

\subsection{Chinese Civic Consciousness in General}

\subsubsection{Citizens' Cognition of Their Own Roles}

Citizens' subject consciousness is firstly reflected in the cognition of their own roles. This role should be a kind of unity of rights and obligations, because "rights, has often been seen as the defining criterion of citizenship" (Richard B. 2008, p. 13), and the constitution stipulates citizens' obligations as well. On the other hand, citizens' subject consciousness should not be reflected in anaclisis but a kind of independence.

When asked "As a citizen of the People's Republic of China, to what extent do you know about your basic rights and obligations?" $4.8 \%$ of the respondents "know well", $14.1 \%$ "know a lot", $56.6 \%$ "know some", $21.3 \%$ "know a little" and 3.4\% "know nothing". It seems that, according to the result, most of the citizens don't know much about their basic rights and obligations, and therefore they seldom consider themselves as independent citizens with appropriate rights and obligations.

When citizens' legitimate rights and interests are infringed, $27.9 \%$ of the respondents will "argue on the basis of reason", $39.4 \%$ "make a complaint to the consumers' association", $4.1 \%$ "revenge the infringer", $17.5 \%$ "confess the bad luck", and $11.1 \%$ will employ "other" ways. The result shows that most of the citizens will try to protect their legitimate rights and interests in appropriate ways.

As for the attitude towards the decisions made by the collective leadership, $33.3 \%$ of the respondents will "actively express their points of view", 10.3\% "won't have much thinking", 35.3\% "won't raise any objections in spite of their different opinions", 17.4\% "absolutely obey the collective decisions" and 3.6\% hold "other" attitudes. From the result, we could see that it is very common for many citizens to depend on authority and to stay out of what hasn't much to do with them.

\subsubsection{Citizens' National Identity}

In the legal sense, an individual should be a citizen of a political community or mainly a citizen of a nation-state, so the national identity should be a very important part of a citizen's civic consciousness.

For the statement "On the whole, China's current system is the most suitable for its national conditions", $8.7 \%$ of the respondents "totally agree", $37.6 \%$ "quite agree", $36.1 \%$ are "not sure", $14.3 \%$ "don't quite agree" and 3.2\% "totally disagree". For another statement "China has made great achievements during more than 30 years of its reform and opening-up", $27.5 \%$ of the respondents "totally agree", $48.8 \%$ "quite agree", $17.6 \%$ are "not sure", $4.7 \%$ "don't quite agree" and $1.4 \%$ "totally disagree". And for the statement "No matter where I go, I will forever keep in mind that I am a member of the big family of the Chinese nation", as many as $62.0 \%$ of the respondents "totally agree", $25.5 \%$ "quite agree", $9.0 \%$ are "not sure", $2.4 \%$ "don't quite agree" and only $1.1 \%$ "totally disagree".

According to the data above, quite a lot of people hold a positive attitude towards "members of the Chinese nation" and "China's great achievements brought by the reform and opening-up policy", which shows that 
citizens' sense of national identity is very strong. However, relatively fewer people think that our current system is consistent with China's national conditions. It is well-known that China has made obvious achievements in economy, politics, culture and education during the past few decades, but some aspects or parts of the system framework still need to be designed better. Citizens' dissatisfaction with the system will lower the sense of identity to the country.

\subsubsection{Citizens' Consciousness of Political Participation}

In order to learn about the overall interest in politics, the respondents are asked to express their attitude to the statement "Political activities are only related to a small number of people, and it's none of my business". $4.8 \%$ of them "totally agree", $11.1 \%$ "quite agree", $20.9 \%$ are "not sure", while $38.8 \%$ "don't quite agree" and $24.4 \%$ "totally disagree", which suggest that most citizens believe that political activities should be part of their own daily life.

Citizens' political consciousness, for the most part, could be reflected by citizens' political participation activities. In order to learn something about citizens' political consciousness, we asked the respondents to select the activities which they had participated in during the past 2 years from the activities given: 1 . Actively concerned yourself about the reports of the National People's Congress and the CPPCC and learn about the main contents; 2. Voted in the election activities held by the villagers' committee/ residents' committee or in your school or working department; 3. Joined in the management of the daily affairs in your own village or community; 4. Joined in the management of the daily affairs in your own school/college/university or working department; 5. Took part in a voluntary activity as a volunteer; 6 . Joined an organization or a group for the sake of a specific ideal or career; 7. Reported something important to the head of your department; 8. Expressed your own ideas or points of view by means of relative groups or organizations; and 9. Proposed your own opinion(s) online (BBS/Blog/QQ etc.). Among all the activities, some of them are actually not political activities. The result shows that in so-called political activities such as activities 1 and 2, citizens do not seem to have much interest, while citizens show greater enthusiasm for other activities such as activities $4,7,8$ and 9 , which relate closely to citizens' own vital interests on the one hand and citizens can easily and conveniently participate in, on the other hand. Though citizens think political activities are important for them, their political participation consciousness is actually not very strong, which will undoubtedly affect their overall political consciousness.

\subsubsection{Citizens' Legal Consciousness}

The market economy is a kind of economy on a legal basis, and therefore a perfect legal system must be developed in order to safeguard the rapid and smooth development of China's market economy under the control of market principles and regulations. And citizens should know, understand and observe the laws so that they could actively maintain their own benefit without illegally infringing upon the rights or interests of others. For the statement "I myself will not violate the laws, so the laws have nothing to do with me", $2.4 \%$ of the respondents "totally agree", $4.9 \%$ "quite agree", $8.0 \%$ are "not sure", $37.7 \%$ "don't quite agree" and $47.0 \%$ "totally disagree". It shows that citizens' cognition degree of the importance of the laws and regulations is comparatively high and they tend to believe that there is a close connection between the laws and their social life.

A very important aspect related to citizens' legal consciousness is involved in the understanding of the legal system and especially the specific articles of laws and regulations. In order to learn about citizens' cognition of some articles of laws, we asked the respondents to decide which of the 9 statements are correct according to their common legal knowledge. The 9 statements are: 1. China's supreme state authority is the CPC Central Committee; 2. The legal age at which Chinese citizens enjoy the right to vote and also the right to be elected is 18; 3. The local government can put forward some suggestions on the decision of the court; 4. A married daughter has a duty to support her parents; 5 . A contract signed by both parties is legal; 6 . An enterprise can hire 15 -year-old persons as workers; 7 . A security guard has the right to search relevant persons; 8 . The rural land can be traded by farmers; and 9 . The realty ownership certificate shall be the evidence for the holder's ownership of a realty. For statements 2, 4, 6, 7 and 8 , more than $80 \%$ of the respondents can decide whether they are correct or wrong; while for statements $1,3,5$ and 9 , only $66.9 \%, 51.2 \%, 65.0 \%$ and $76.3 \%$, respectively, of the respondents can correctly tell whether they are right or wrong. From the result above, we could see that some citizens' degree of knowledge of the commonly used laws and regulations is not so high as expected.

In addition to the knowledge of the provisions for laws and regulations, citizens' legal consciousness should be involved in understanding of the seriousness of the law and using the law to protect their own rights or interests. For the statement "On criminal law enforcers, regardless of the seriousness of the crime, heavy penalties should be imposed", $17.2 \%$ of the respondents "totally agree", $17.7 \%$ "quite agree", $15.0 \%$ are "not sure", $36.7 \%$ "don't 
quite agree" and $13.3 \%$ "totally disagree", which shows that the principle "everyone is equal before the law" is not deeply impressed in the mind of some people. For the question "Before establishing the work or business relationship, will you sign a contract with your working unit, the labour contractor or your business partners?", the answer of $31.6 \%$ of the respondents is "Absolutely", $24.0 \%$ "Probably ", 22.2\% "Not sure", $14.7 \%$ "Probably not", and $7.6 \%$ "Absolutely not". It suggests that some people, due to various reasons, may not put their work or labour relationship within the constraint of laws and regulations.

\subsubsection{Citizens' Moral Consciousness}

Morality or ethic, in a broad sense, includes social morality, professional morals, family virtues, individual morality, and also some other levels of morality existing in public life. In the survey, we mainly study citizens' moral consciousness from the perspective of behavioural norms, professional morals and individual integrity.

When asked "As a pedestrian, when crossing the street in the city, to what extent will you follow the instructions of traffic lights?", $38.9 \%$ of the respondents "always "follow the instructions, $51.9 \%$ "most of the time", $7.5 \%$ "seldom", and 1.7\% "never" follow the instructions of traffic lights. Most people tend to abide by the rules in public, but more than half of the respondents in the survey abide by the rules only "most of the time", which shows that most people actually have a kind of fluke mind before the principles or rules, that is to say, it is likely that most people are unwilling to be controlled by the rules if not supervised.

For the statement "Instead of seeking for great accomplishment, I simply hope that I would do nothing wrong in my work", $7.5 \%$ of the respondents "totally agree", $26.5 \%$ "quite agree", $20.3 \%$ are "not sure", $35.0 \%$ "don't quite agree" and $10.7 \%$ "totally disagree". Though half of the respondents think that they will try their best to do well what they should do, yet another $1 / 3$ may perform their duty in a perfunctory manner.

For the statement "In today's society, we might not trust most of the people readily as well", $11.4 \%$ of the respondents "totally agree", $37.5 \%$ "quite agree", $24.8 \%$ are "not sure", $24.0 \%$ "don't quite agree" and 2.3\% "totally disagree". We could not say that those who hold the point of view above are all untrustworthy, but at least it suggests that during today's social transformation period in China, there exists a serious lack of social integrity.

And for the statement "The market economic system is a system to maximize the economic benefit", $5.6 \%$ of the respondents "totally agree", $27.3 \%$ "quite agree", $40.0 \%$ are "not sure", $22.5 \%$ "don't quite agree" and $4.6 \%$ "totally disagree". The cognition of the market economic system can, to some extent, reflect citizens' behaviour and mentality under the condition of the market economy. China is now constructing a new market economic system, and in this process the economic humanity of different market entities has been fully demonstrated, but some people place an undue emphasis on the pursuit of economic benefit without keeping the moral humanity in mind. $40 \%$ of the respondents have some reservations and they are not sure whether they should agree to the statement or not, which suggests that under the condition of market economy, the conflict between the rationality of economic humanity and the restriction of moral humanity causes a kind of confusion in their mind.

\subsubsection{Citizens' Ecological Civilization Consciousness}

Today, the rapid development of science and technology and constant improvement of productivity level greatly enhance human's ability to conquer and transform nature. However, science and technology is a double-edged sword and it could also push human to the opposite side of nature, which they depend upon to survive. With the aid of high technology, man tries all possible means to develop the limited natural resources and indiscriminately destroys the ecological environment, which brings about frequent natural disasters and seriously affects the survival environment of us and the sustainable development of the whole society. Therefore, it is very important for us to handle the relationship between man and nature correctly and establish a proper ecological civilization consciousness in the process of modernization.

For the statement "We should do everything possible to exploit and utilize natural resources", $10.4 \%$ of the respondents "totally agree", $18.3 \%$ "quite agree", $15.9 \%$ are "not sure", $35.1 \%$ "don't quite agree" and 20.3\% "totally disagree". Most people believe that man should not consider himself as the master of nature, put economic interest above other interests and excessively exploit natural resources.

But when asked "Will you sort out the waste before you throw rubbish into a classification dustbin?", $19.7 \%$ of the respondents answer "Absolutely", 34.4\% "Probably ", 17.9\% "Not sure", 23.4\% "Probably not", and 4.7\% "Absolutely not". And for the question "When you do shopping, to what extent will you use disposable plastic shopping bags?", $7.9 \%$ of the respondents say that they will use disposable plastic shopping bags "every time", $43.9 \%$ "most of the time", $43.6 \%$ "seldom" and $4.5 \%$ "never". The results show that citizens do not really care whether these behaviours will cause some environmental hazards or not. They may not, for the sake of their own 
convenience, consciously protect the environment in their daily life. On the whole, though citizens have known clearly about the factors affecting the natural ecological environment, yet the ecological civilization consciousness of most citizens is not really strong.

\subsubsection{Citizens' Global Citizenship}

With the globalization of economy, the multi-polarization of political structure and the rapid development of information and network technology, the links in economy, politics, culture and so forth between different countries are becoming closer and closer and also more and more frequent. Globalization is "the inexorable integration of markets, nation-states and technologies to a degree never witnessed before-in a way that is enabling individuals, corporations and states to reach around the world farther, deeper and cheaper than ever before"(Friedman, T. 2000, p. 9). People not only live in their own countries, but also live in an international community, so it is necessary for the global citizens to consider, analyze and solve something in the work and life from a global perspective.

When asked what kind of things citizens are most concerned about, $10.2 \%$ of the respondents reply that they are most concerned about what happen in "their neighbourhood", $14.0 \%$ "their communities or villages", $17.9 \%$ "their cities or counties", $36.9 \%$ "the whole country", and only $21.0 \%$ are most concerned about what happen in "the whole world". And for the question "How often do you learn about the major events that happen in other countries or regions? ", $15.0 \%$ of the respondents "usually" learn about the major events in other countries or regions, $32.6 \%$ "most of the time", $29.3 \%$ "seldom", $1.7 \%$ "never", and $21.5 \%$ of them are not sure about it. From the results above, we could see that citizens do not focus much of their attention on the events in the places far away from them. People always regard themselves as citizens of a nation-state, but they seldom regard themselves as citizens of the "global village", that is to say, the citizens' consciousness of global citizenship is relatively weak.

\section{Conclusions and Discussion}

According to the survey, it is quite clear that contemporary Chinese citizens lack the civic consciousness in accordance with the requirement of the development of the society on the whole. Citizens do not really confirm their citizenship with independent personality and equal status in the depth of their hearts and meanwhile they still have a kind of strong psychological dependence. Although there have been more ways and expedite channels for citizens to speak out their ideas and opinions and most citizens do not think that politics is just involved with a few elites of the society, yet in reality most of them are not willing to actively and enthusiastically participate in political activities and they show an attitude of indifference most of the time. After a few rounds of legal publicity and education in China, the administrative departments' awareness and ability to carry out the official duties and make decisions and policies in accordance with the law have been greatly enhanced, but as far as the general public, they do not know much about the laws and regulations, even those closely related to their daily life, and therefore most of them could not consciously and properly use the weapon of law to safeguard their legitimate rights and interests. In moral terms, due to some citizens' extreme individualism and their unawareness of their roles of the "social beings", the moral consciousness of some citizens is poor and some of them are generally in lack of integrity and social responsibility. In terms of ecological consciousness, some of the citizens only live for the present without considering the long-term interests of others and their future generations, and they try all means to maximize the economic benefit of their own at the expense of over-exploitation of the limited natural resources and destruction of the ecological environment in our earth. And in the era of globalization and informatization, China has found closer ties in economy and politics and interpenetration and mutual tolerance in culture with the other parts of the world, but the visual field of some citizens is still confined within a narrow range most of the time, which is detrimental to the communication in all respects and at all levels between China and the world.

Of course, contemporary Chinese civic consciousness is not developed overnight, and it is inevitably affected by a variety of factors: political and economical systems and cultural background in so long a history of feudal society in China, the educational systems and contents, the objectives and methods of citizenship education, individual educational levels, and so on. In order to enhance the civic consciousness in accordance with a modern society, we must consider seriously all the influencing factors mentioned above and make a series of improvements in different respects. Only in this way, can we achieve the enhancement of Chinese civic consciousness and also achieve the modernization of individuals or the all-round development of individuals, which is the key to realize the modernization of the society as a whole.

\section{Acknowledgements}

I am grateful to Professor Xiao Ping, Professor Tong Huarong and Doctor Fang Gang for their critical comments 
and suggestions in the preparation and modification process of my questionnaire. I want to thank especially Michael G. Fischer, former director of Project Citizen and Professional Development for the Center for Civic Education, for his new advice in our discussion on the topic of civic consciousness. My thanks will also be given to Tie Huaijiang, He Yan, Geng Yajun, Li Lin, Yang Junming, Yang Qiyun, Tong Huafu, Tong Huali, Bai Rongchun, Zhang Huaxian, Huang Ping, etc. for their strong support and unselfish help in my survey.

\section{References}

Friedman, T. (2000). Understanding globalization: The lexus and the olive tree. New York: Anchor Books.

Hu Jintao. (2007). Hold High the Great Banner of Socialism with Chinese Characteristics and Strive for New Victories in Building a Moderately Prosperous Society in All Respects. Retrieved February 3, 2012, from http://news.xinhuanet.com/newscenter/2007-10/24/content_6938568_5.htm

Huddleston, T., \& Kerr D. (Eds.). (2006). Making sense of citizenship. London: Hodder Education.

Kathleen Knight-Abowitz. (2009). Citizenship Education. In: Eugene F. Provenzo Jr., et al. (Eds.). Encyclopedia of the social and cultural foundations of education (Volumes 1-3). CA: SAGE Publications, Inc., 128-132

Monalisa M. Mullins. (2008). Civic Education. In: F. Clark Power, et al. (Eds.). Moral education: a handbook. Westport, CT: Praeger Publishers, 79-80

Richard Bellamy. (2008). Citizenship: a very short introduction. New York: Oxford University Press Inc. 